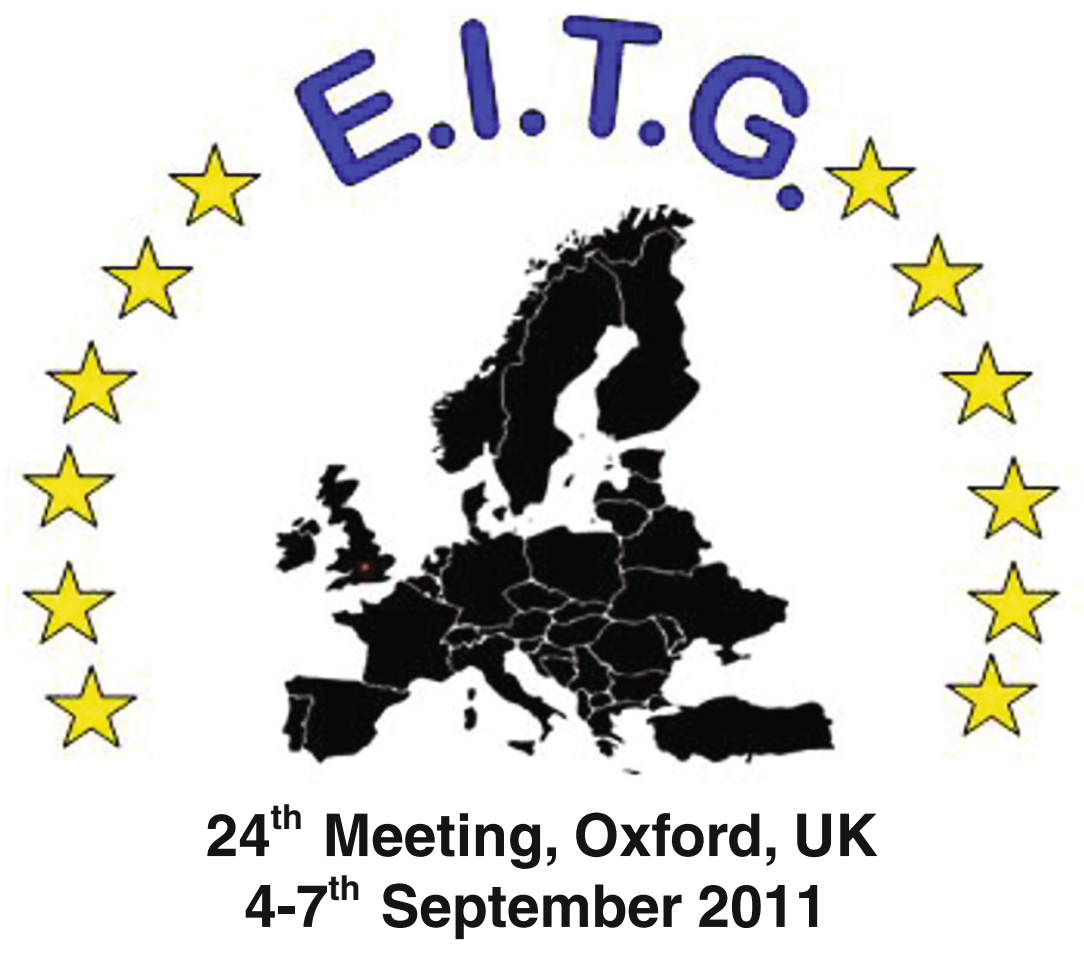

\title{
PROCEEDING PAPERS AND ABSTRACTS
}

\author{
Organiser: David Meredith \\ Oxford Brookes University, UK
}

The EITG thank the following for their generous support of the meeting

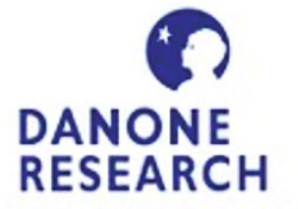

CENTRE FOR SPECIALISED NUTRITION

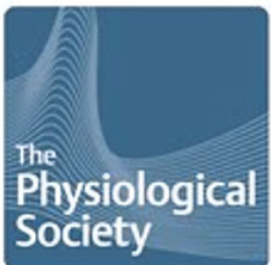

Society

\section{OXFORD}

UNIVERSITY PRESS

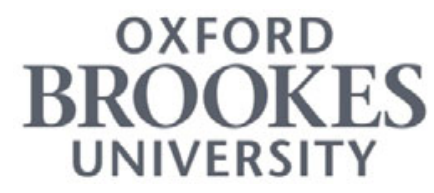

